\title{
tRNA diversification among uncultured archeon clones
}

\author{
Mohammad Mahfuz Ali Khan Shawan ${ }^{1 *}$, Md. Ashraful Hasan', Raihana Yesmin ${ }^{1}$, Tareq Hossan ${ }^{1}$, \\ Md. Mozammel Hossain', Md. Mahmudul Hasan', Afroza Parvin', Mahbubul Morshed', Nahiyan \\ Mohammad Salauddin', Satya Ranjan Sarker ${ }^{3}$, Md. Nazibur Rahman', S. M. Badier Rahman ${ }^{1}$
}

${ }^{1}$ Department of Biochemistry and Molecular Biology, Jahangirnagar University, Savar, Dhaka-1342, Bangladesh; ${ }^{2}$ Department of Soil, Water and Environment, University of Dhaka, Bangladesh; ${ }^{3}$ Department of Biotechnology and Genetic Engineering, Jahangirnagar University, Savar, Dhaka-1342, Bangladesh; Mohammad Mahfuz Ali Khan Shawan - E-mail: mahfuz_026shawan@juniv.edu; *Corresponding author

Received June 25, 2018; Revised July 5, 2018; Accepted July 31, 2018; Published July 31, 2018

doi: $10.6026 / 97320630014357$

\begin{abstract}
:
Whole genome sequences (DNA sequences) of four uncultured archeon clones (1B6:CR626858.1, 4B7:CR626856.1, 22i07:JQ768096.1 and 19c08:JQ768095.1) were collected from NCBI BioSample database for the construction of digital data on tRNA. tRNAscan-SE 2.0 and ENDMEMO tools were used to identify and sketch tRNA structure as well as calculate Guanine-Cytosine (GC) percentage respectively. Eight true/functional tRNAs were identified from above 4 sequences which showed cove score greater than $20 \%$ with no variable loop. The tRNAs from the uncultured archeon clones were classified as Ala, Arg, Ile, Thr, Pro and Val type tRNA with cove score ranging from $34.22 \%-79.03 \%$. The range of GC content was found $42.89 \%-56.91 \%$; while tRNA contributed GC content ranging from $52 \%-64.86 \%$ to the total GC content in these sequences. The data fabricated in this study could be very useful for studying the diversity of tRNA among prokaryotes.
\end{abstract}

Keywords: Uncultured archeon clones; true/functional tRNA; NCBI BioSample database; GC percentage; tRNAscan-SE 2.0 tool; ENDMEMO GC calculating tool; tRNA type; cove score

\section{Background:}

Transfer RNA (tRNA), a tiny non-coding RNA comprises of about 75-95 nucleotides (nts). It is ubiquitous in all the three domains of life and concerned with translation machinery in deciphering mRNA to protein [1]. A secondary structure made up of a terminal helical stem and three hairpin loops is the distinguishing features of all tRNAs. The functional parts of a tRNA include the anticodon triplets that interpret the mRNA codons and the 3' CCA nts that is charged with corresponding amino acid delivering into the ribosome during translation [2]. The highly complex classes of genes within tRNA are still evolving and the analysis of tRNA diversity is an exhilarating topic in the field of molecular evolution [3]. Diversification of these ancient macromolecules (tRNA) seems to be co-evolved with RNA splicing endonucleases under string evolutionary pressure to which diverse genetic lineages were adapted in translation. Mitochondrial oxidative environment also probably had the influence on tRNA evolution [4]. Archeal genome reveals ISSN 0973-2063 (online) 0973-8894 (print)

Bioinformation 14(7): 357-360 (2018) three types of tRNA genes namely non-intronic tRNA (encoded on a single gene with no intron), intronic tRNA (encoded on a single gene with 1-3 introns) and split tRNA (found only in hyperthermophilic archeal parasite and encoded on separate genes). The evolutionary study of tRNA genes clarifies that ancestral tRNA was encoded on a single gene or separate genes [3]. Thus, understanding of diverse true/functional tRNA fragments will help us to detect the systematic classification of fragments in the context of full-length tRNA genes. The knowledge on evolved tRNA will also guide us to solve the different quests such as whether it is evolved from common ancestor, or whether it is lost during evolution.

\section{Dataset:}

Whole genome sequences of four uncultured archeon clones (CR626858.1, CR626856.1, JQ768096.1 and JQ708095.1) were downloaded in FASTA format through NCBI's BioSample database. Data on tRNA was detected and scrutinized through BIOMEDICAL INFORMATICS 


\section{BIOINFORMATION \\ Discovery at the interf ace of physical and biological sciences}

tRNAscan-SE 2.0 tool. Perceived tRNAs were categorized into different types on the basis of coded amino acid and cove score. ENDMEMO GC content calculator was used to generate data on GC content in percentage.

Experimental design, materials and methods:

Complete DNA sequences of four uncultured archeon clones were retrieved from NCBI (National Center for Biotechnology Information) BioSample database via Nucleotide DNA database and stored in FASTA format [5]. Detected tRNAs were classified into different classes based on amino acid code and cove score [69]. ENDMEMO GC calculating tool was used to generate the data on GC percentage for both the whole genome sequences and detected tRNAs [10]. ENDMEMO GC plotting tool was utilized to illustrate pattern of GC allocation through graphical representations. Within the GC plot, upper and lower red lines specify highest and lowest percentage of GC allotment, while middle blue line demonstrates average GC percentage distributed in DNA sequence [11-14].
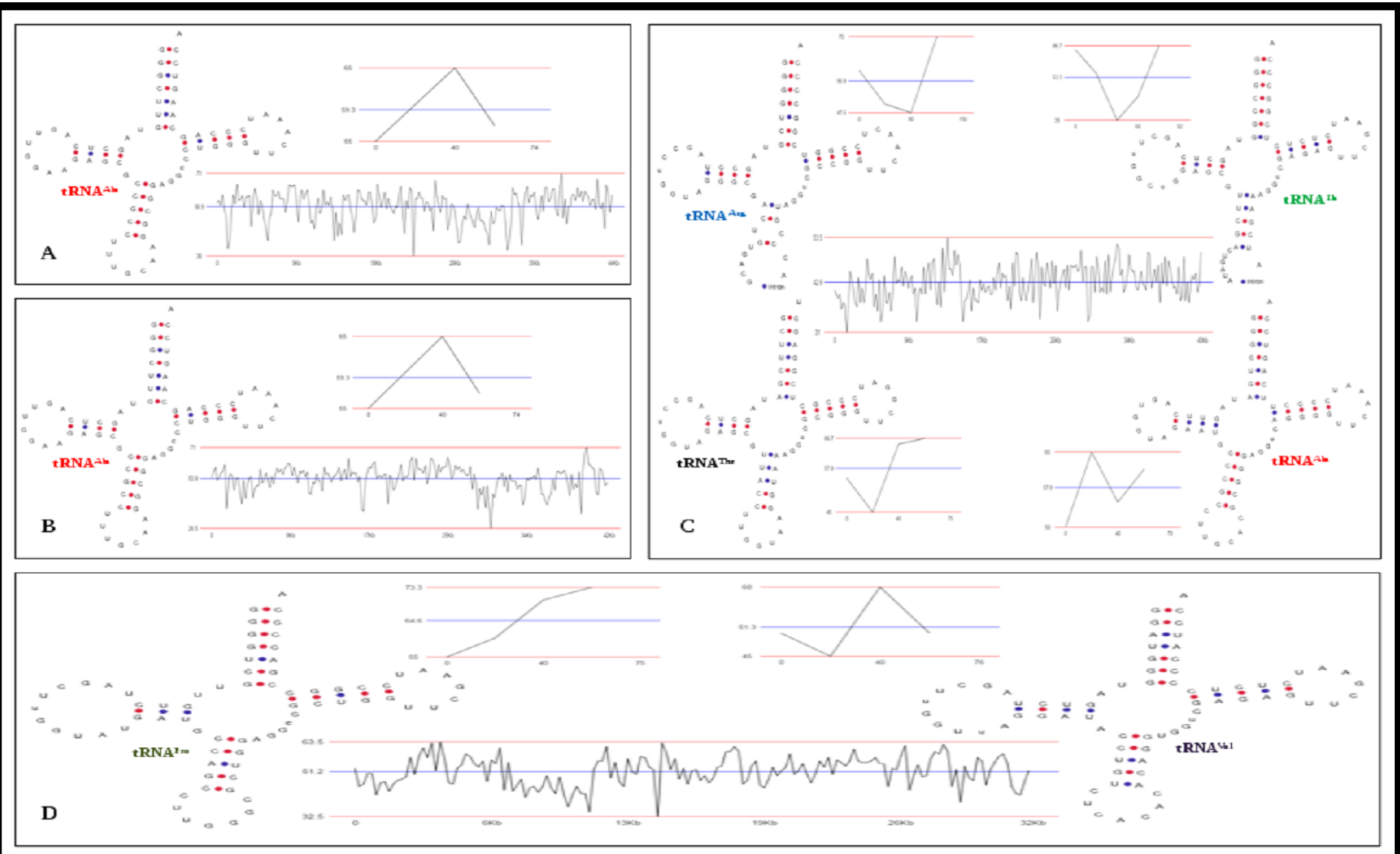

Figure 1: tRNA secondary structure and GC allocation through graphical representations in four uncultured archeon clones detected by tRNAscan-SE 2.0 and ENDMEMO GC calculator. A) 1B6:CR626858.1; B) 4B7:CR626856.1; C) 22i07:JQ768096.1 and D) 19c08:JQ768095.1

\section{Results \& discussion:}

In this study, detection, classification as well as function and structure prediction of tRNA genes within four uncultured archeon clones were achieved by using newly developed tRNAscan-SE 2.0 tool, which has advanced state of art methodology in tRNA gene investigation and uses genomic tRNA database having rich new content [15]. This online tool classifies tRNA into different types depending on amino acid code and cove score [6]. As shown in Table 1, this investigation identified single Ala type tRNA (tRNAAla) having cove score of 78.59\% with no introns for each of CR626858.1 and CR626856.1. Additionally, this tool detected four tRNAs (tRNAAla, tRNAArg, ISSN 0973-2063 (online) 0973-8894 (print)

Bioinformation 14(7): 357-360 (2018)
tRNA ${ }^{\text {Ile }}$ and tRNAThr) having cove score ranging from $34.22 \%$ $79.03 \%$ with two introns (tRNA ${ }^{A r g}$ and tRNAlle), and two tRNAs (tRNA ${ }^{\text {Pro }}$ and tRNAVal) having cove score ranging from $64.70 \%$ $74.24 \%$ with no introns for JQ768096.1 and JQ768095.1 respectively. Thus, it is evident that, all of these tRNAs have cove score more than $20 \%$ and can be considered as true/functional tRNA. Furthermore, six out of eight predicted tRNAs having no introns imply non-intronic while rest of the two predicted tRNAs with introns indicate intronic tRNAs. Previously, Rekadwad et al. using complete genome sequences of two uncultured archaea and ten uncultured bacteria observed a total of seven archaeal tRNAs (tRNAAla, tRNAArg and tRNACys) having cove score

$$
\text { BIOMEDICAL }
$$

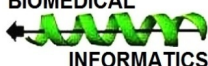




\section{BIOINFORMATION}

ranging from $54.34 \%-75.97 \%$ and fourty eight bacterial tRNAs (tRNA Ala, tRNACys, tRNAGln, tRNAGlu, tRNA ${ }^{\text {Ile, }}$, tRNALeu, tRNALys, tRNA ${ }^{\text {Met, }}$ tRNA ${ }^{\text {Phe, }}$ tRNA ${ }^{\text {Pro, }}$ tRNA ${ }^{\text {Ser }}$ and tRNA $^{\text {Val }}$ ) having cove score ranging from $58.09 \%-97.15 \%$. In both cases, no introns within the tRNAs were obtained [9]. Interestingly, no selenocysteine tRNAs (TCA), suppressor tRNAs (CTA and TTA), pseudogenes and tRNAs with unknown isotypes were found in both the present investigation and the study carried out by Rekadwad et al. [9]. Determination of GC content within the whole genome as well as tRNA is very much crucial, because extremely high or low level of genomic GC content may produce an unassigned codon by losing a tRNA [16]. As shown in Figure 1, GC allocation through graphical representations reveal approximately $56.9 \%, 53.9 \%, 42.9 \%$ and $51.2 \%$ of GC in the 1B6:CR626858.1， 4B7:CR626856.1，22i07:JQ768096.1 and 19c08:JQ768095.1 respectively, with tRNAs having GC ranging from $51.3 \%-64.6 \%$. This finding is consistent with the observation of Rekadwad et al. who also found GC content approximately $43 \%$ for archaeal genome, wherein archaeal tRNA contributed $60.4 \%-64.2 \%$ GC to the total GC content [9].

Table 1: Results for the analysis of true/functional tRNA detected in four uncultured archeon clones using tRNAScan-SE 2.0

\begin{tabular}{|c|c|c|c|c|c|c|c|c|c|}
\hline Sequence name & $\begin{array}{l}\text { No. of } \\
\text { tRNA }\end{array}$ & $\begin{array}{c}\text { tRNA } \\
\text { begins }\end{array}$ & $\begin{array}{c}\text { Bounds } \\
\text { end }\end{array}$ & tRNA type & Anti-codon / at & $\begin{array}{l}\text { Intron } \\
\text { begins }\end{array}$ & $\begin{array}{c}\text { Bounds } \\
\text { end }\end{array}$ & $\begin{array}{c}\text { Cove } \\
\text { score }(\%)\end{array}$ & $\begin{array}{c}\text { tRNA } \\
\text { length (bp) }\end{array}$ \\
\hline 1B6:CR626858.1 & 1 & 30548 & 30476 & Ala & TGC/30515-30513 & 0 & 0 & 78.59 & 73 \\
\hline 4B7:CR626856.1 & 1 & 33664 & 33592 & Ala & TGC/33631-33629 & 0 & 0 & 78.59 & 73 \\
\hline \multirow[t]{4}{*}{ 22i07:JQ768096.1 } & & 12593 & 12741 & Arg & ACG/12626-12628 & 12629 & 12705 & 34.22 & 149 \\
\hline & & 25074 & 25164 & Ile & GAT/25109-25111 & 25113 & 25128 & 67.36 & 91 \\
\hline & & 26821 & 26894 & Thr & GGT/26855-26857 & 0 & 0 & 74.14 & 74 \\
\hline & 4 & 24399 & 24328 & Ala & TGC/24367-24365 & 0 & 0 & 79.03 & 72 \\
\hline \multirow[t]{2}{*}{ 19c08:JQ768095.1 } & & 19803 & 19730 & Pro & TGG/19769-19767 & 0 & 0 & 64.70 & 74 \\
\hline & 2 & 2177 & 2103 & Val & CAC/2142-2140 & 0 & 0 & 74.24 & 75 \\
\hline
\end{tabular}

\section{Conclusion:}

This study identifies and analyzes true/functional tRNAs using whole genome sequences (complete DNA sequences) that has spawned novel data on true tRNA diversity among the four uncultured archeon clones. Data on GC content and digitization of these novel tRNAs appear to be white snow for research on tRNA and made available to users.

\section{Conflict of interest:}

The authors do not declare any competing interest.

\section{Acknowledgements:}

This research was supported by Department of Biochemistry and Molecular Biology, Jahangirnagar University, Savar, Dhaka 1342, Bangladesh.

\section{References:}

[1] Maizels N \& Weiner AM, Proc. Natl. Acad. Sci. 1994 91:6729 [PMID: 8041690]

[2] Goodenbour JM \& Pan T, Nucleic Acids Res. 2006, 34:6137 [PMID: 17088292]

[3] Fujishima K et al. PLoS One. 2008, 3:e1622 [PMID: 18286179]

[4] Pütz J et al. FEBS Lett. 2010, 584:350 [PMID: 19931530]
[5] Shawan MMAK et al. Data in Brief. 2016, 9:602 [PMID: 27766287]

[6] Targanski I \& Cherkasova V. RNA. 2008, 14:1095 [PMID: 18441051]

[7] Silva FJ et al. Nucleic Acids Res. 2006, 34:6015 [PMID: 17071718]

[8] Avni D et al. Nucleic Acids Res. 1997, 25:995 [PMID: 9023110]

[9] Rekadwad BN \& Khobragade CN, Data in Brief. 2016, 7:1538 [PMID: 27222849]

[10] Satapathy SS et al. Microbiol. Res. 2010, 165:232 [PMID: 19713091]

[11] Rekadwad BN \& Khobragade CN, Data in Brief. 2016, 7:1306 [PMID: 27141529]

[12] Rekadwad BN \& Khobragade CN, Data in Brief. 2016, 6:53 [PMID: 26793757]

[13] Rekadwad BN \& Khobragade CN, Data in Brief. 2016, 7:1524 [PMID: 27222847]

[14] Rekadwad BN \& Khobragade CN, Data in Brief. 2016, 7:1511 [PMID: 27182549]

[15] Lowe TM \& Chan PP, Nucleic Acids Res. 2016, 44:54 [PMID: 27174935]

[16] Kano A et al. J. Mol. Biol. 1993, 230:51 [PMID: 8450550]

Edited by P Kangueane Citation: Shawan et al. Bioinformation 14(7): 357-360 (2018) License statement: This is an Open Access article which permits unrestricted use, distribution, and reproduction in any medium, provided the original work is properly credited. This is distributed under the terms of the Creative Commons Attribution License 


\section{BIOINFORMATION}

Discovery at the interface of physical and biological sciences
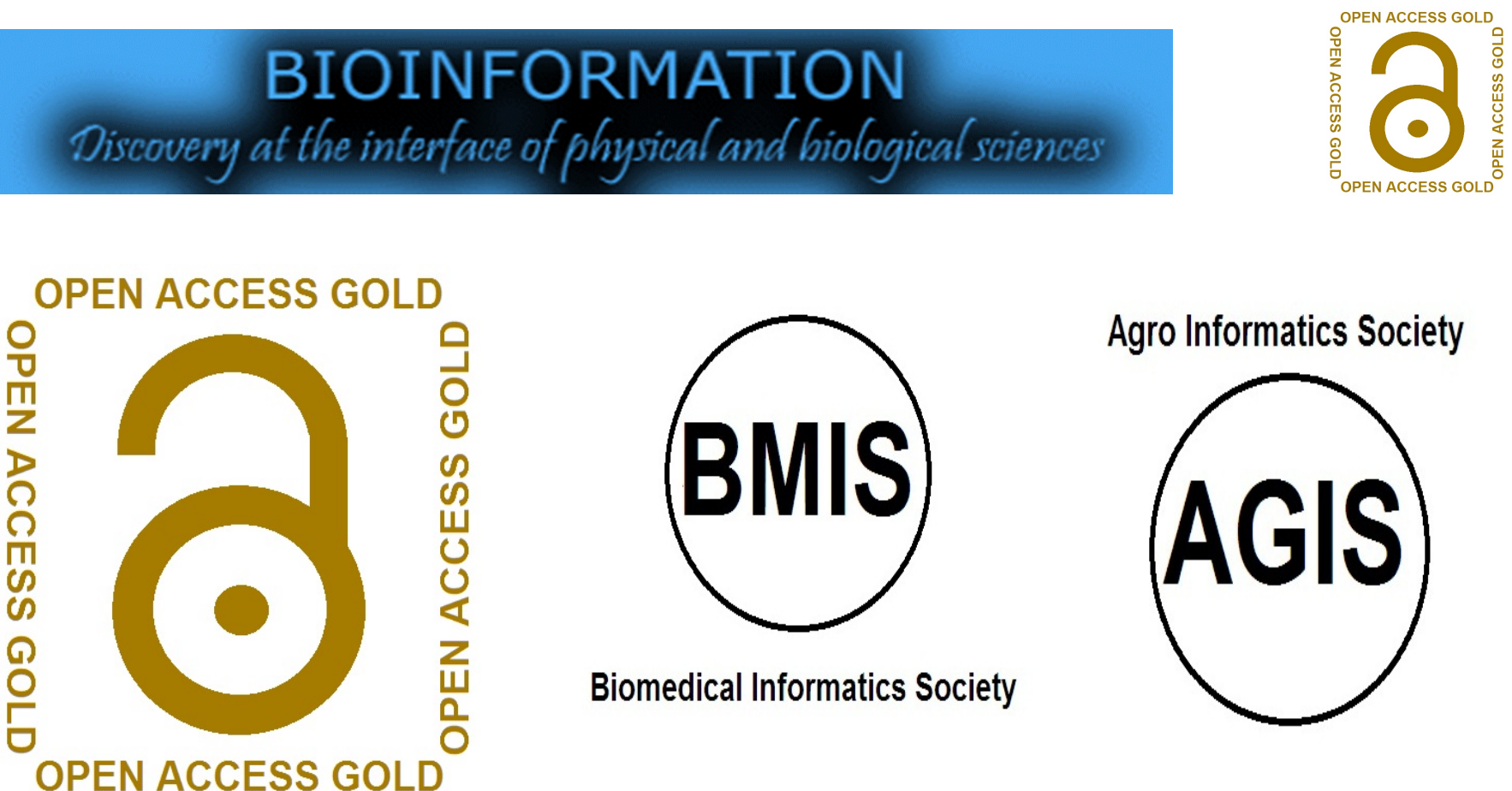

Agro Informatics Society

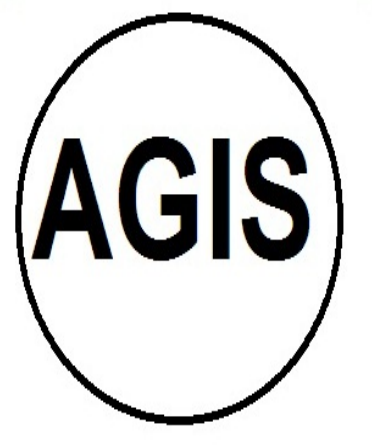

Journal 